\title{
Study of Regularities and Optimization of the Process of Fir Wood Peroxide Delignification in the Medium of "Acetic Acid - Water" in the Presence of Sulfuric Acid Catalyst
}

\author{
Olga V. Yatsenkova*a, \\ Andrei M. Skripnikova and Boris N. Kuznetsov ${ }^{\mathrm{a}, \mathrm{b}}$ \\ anstitute of Chemistry and Chemical Technology SB RAS \\ FRC "Krasnoyarsk Science Center SB RAS" \\ 50/24 Akademgorodok, Krasnoyarsk, 660036, Russia \\ ${ }^{b}$ Siberian Federal University \\ 79 Svobodny, Krasnoyarsk, 660041, Russia
}

Received 30.10.2019, received in revised form 02.11.2019, accepted 22.11.2019

The work describes a one-stage method of cellulose obtaining from fir wood based on peroxide delignification of wood under mild conditions $\left(100^{\circ} \mathrm{C}\right.$, atmospheric pressure) in the presence of acetic acid, water and catalyst of $2 \% \mathrm{wt} . \mathrm{H}_{2} \mathrm{SO}_{4}$. The possibility of obtaining cellulose with a residual lignin content $<1 \% \mathrm{wt}$. at a low concentration of hydrogen peroxide (3\% wt.) in the reaction medium was established. The optimal concentrations of reagents $\left(\mathrm{H}_{2} \mathrm{O}_{2}-3 \%\right.$ wt., $\mathrm{CH}_{3} \mathrm{COOH}-38.9 \%$ wt. $)$ and the duration of the process $(4 h)$ were determined by experimental and calculation methods. This conditions provide a high yield of cellulose product ( $\geq 45 \% \mathrm{wt}$.) with a low content of residual lignin $(<1 \%$ wt.). The composition and structure of fir cellulose was studied by chemical analysis and by FTIR and SEM methods. The cellulosic product which was obtained in optimal process conditions is high-quality cellulose.

Keywords: fir wood, peroxide delignification, acetic acid, optimization, cellulose.

Citation: Yatsenkova O.V., Skripnikov A.M., Kuznetsov B.N. Study of regularities and optimization of the process of fir wood peroxide delignification in the medium of "acetic acid - water" in the presence of sulfuric acid catalyst, J. Sib. Fed. Univ. Chem., 2019, 12(4), 590-603. DOI: 10.17516/1998-2836-0154.

(C) Siberian Federal University. All rights reserved

* Corresponding author E-mail address: Yatsenkova@icct.ru,inm@icct.ru 


\title{
Изучение закономерностей и оптимизация
}

\author{
процесса пероксидной делигнификации древесины ели \\ в среде «уксусная кислота - вода» \\ в присутствии сернокислотного катализатора
}

\author{
О.В. Яценкова ${ }^{\text {a }, ~ А . М . ~ С к р и п н и к о в ~}{ }^{\text {a }}$ Б.Н. Кузнецов ${ }^{\mathrm{a}, \tilde{\sigma}}$ \\ ${ }^{a}$ Институт химии и химической технологии СО РАН \\ ФИЦ «Красноярский научный чентр СО РАН» \\ Россия, 660036, Красноярск, Академгородок, 50/24 \\ ${ }^{6}$ Сибирский федеральный университет \\ Россия, 660041, Красноярск, пр. Свободный, 79
}

В работе описан одностадийный способ получения целлюлозы из древесины ели, основанный на пероксидной делигнификации древесины в мягких условиях $\left(100{ }^{\circ} \mathrm{C}\right.$, атмосферное давление) в среде уксусной кислоты, воды и катализатора $2 \%$ мас. $\mathrm{H}_{2} \mathrm{SO}_{4}$. Установлена возможность получения иеллюлозы с содержанием остаточного лигнина <1\% мас. при низкой концентрации пероксида водорода (3\% мас.) в реакционной среде. Экспериментальными и расчетными методами определены оптимальные концентрации реагентов $\left(\mathrm{H}_{2} \mathrm{O}_{2}-3 \%\right.$ мас., $\mathrm{CH}_{3} \mathrm{COOH}-$ 38,9 \% мас.) и продолжительность процесса (4 ч), обеспечивающие получение иеллюлозного продукта с высоким выходом ( $\geq 45 \%$ мас.) и низким содержанием остаточного лигнина (<1 \% мас.). Состав и строение целлюлозы ели изучены методами химического анализа, ИКС и СЭМ. Установлено, что иеллюлозный продукт, полученный при оптимальных условиях процесса, является высококачественной целлюлозой.

Ключевые слова: древесина ели, пероксидная делигнификация, уксусная кислота, оптимизация, иеллюлоза.

\section{Введение}

Ель обыкновенная (Picea abies) - одна из основных лесообразующих пород деревьев на территории России и широко используется в качестве сырья для получения целлюлозы. Характерной особенностью хвойной древесины по сравнению с другими видами растительного сырья является содержание большего количества лигнина [1]. Это обстоятельство делает ее более устойчивой к воздействию делигнифицирующих химических реагентов по сравнению с лиственной древесиной. Поэтому актуальной задачей признана оптимизация процесса делигнификации, обеспечивающего возможность получения качественной целлюлозы из древесины ели при разумных затратах энергии и химических реагентов.

Делигнификация - ключевая стадия процесса получения целлюлозы из древесины. Традиционные методы получения целлюлозы характеризуются многостадийностью, использованием опасных серо- и хлорсодержащих делигнифицирующих реагентов, повышенными температурой, давлением и расходом воды [2].

$$
-591-
$$


Новые методы получения целлюлозы основаны на процессах окислительной каталитической делигнификации лигноцеллюлозного сырья с использованием таких «зеленых» окислителей, как пероксид водорода [3], кислород [4 ]. Кислород хорошо окисляет лигнин, однако используется, как правило, в многостадийных процессах, что усложняет технологию. Кислородная делигнификация, по сути, является промежуточным этапом процесса получения крафтцеллюлозы и ее отбеливания [5].

В работах [6] и [7] описан процесс удаления лигнина из древесины с использованием пероксида водорода. Показана возможность получения в одну стадию качественной целлюлозы с содержанием остаточного лигнина $\leq 1$ \% мас. из осины, березы, пихты и лиственницы при делигнификации в среде разбавленной уксусной кислоты и пероксида водорода в присутствии сернокислотного катализатора при температуре $120-130{ }^{\circ} \mathrm{C}$.

Возможность снижения до $100{ }^{\circ} \mathrm{C}$ температуры одностадийной пероксидной делигнификации древесины осины и сосны в среде «уксусная кислота-вода» в присутствии катализатора $2 \%$ мас. $\mathrm{H}_{2} \mathrm{SO}_{4}$ и получения качественной целлюлозы установлена в работах [8-10]. В оптимальных условиях процесса пероксидной делигнификации древесины перечисленных пород концентрация пероксида водорода в реакционной среде составила $4.3 \%$ мас. для осины и $5.3 \%$ мас. для сосны. При делигнификации древесины часть пероксида водорода теряется вследствие его распада с выделением молекулярного кислорода, а уксусная кислота может быть практически полностью регенерирована [11]. Для улучшения экономики процесса пероксидной делигнификации древесины необходимо снижать расход пероксида водорода.

Цель настоящей работы состояла в изучении закономерностей процесса делигнификации древесины ели, имеющей повышенное содержание лигнина, и определении оптимальных условий получения качественной целлюлозы с выходом не менее 45 \% мас., низким содержанием остаточного лигнина и гемицеллюлоз при минимальной концентрации пероксида водорода в реакционной среде. Численная оптимизация процесса делигнификации проведена методом полного факторного эксперимента, который позволяет анализировать эффекты нескольких независимых переменных одновременно [12].

\section{Экспериментальная часть}

В качестве исходного сырья для получения целлюлозного продукта использовали опилки (фракция 2.5-5 мм) средней стволовой части древесины ели, произрастающей в Красноярском крае. Химический состав исходной древесины, определенный с использованием традиционных методик [13] (мас.\% от абс. сух. древесины): целлюлоза 44.4, лигнин 30.6, гемицеллюлозы 22.6, экстрактивные вещества 1.8, зола 0.6.

Делигнификацию древесины ели и определение выхода полученного целлюлозного продукта проводили по методике, описанной в работе [10]. Содержание целлюлозы и гемицеллюлоз в образцах устанавливали по методике [14], для чего разделяли легко- и трудногидролизуемые полисахариды, используя различные условия гидролиза. Индивидуальный состав и содержание моносахаров в полученных гидролизатах исследовали хроматографическим методом с помошью газового хроматографа VARIAN-450 GC с пламенно-ионизационным детектором и капиллярной колонки VF- $624 \mathrm{~ms}$ длиной 30 м, внутренним диаметром 0,32 мм. Пробу гидролизата предварительно подвергали дериватизации по методике [15] с образованием три- 
метилсилильных производных. Содержание лигнина в целлюлозном продукте определяли по методу Класона с 72\%-ным раствором $\mathrm{H}_{2} \mathrm{SO}_{4}$ [16].

ИК-спектры целлюлозы снимали на ИК-Фурье-спектрометре Tensor 27 (фирма Bruker, Германия) в области 4000-400 см-1. Обработку спектральной информации проводили с использованием пакета программы OPUS, версия 5.0.

Изучение морфологии поверхности целлюлозы осуществляли с помощью сканирующего электронного микроскопа (СЭМ) ТМ-3000 (Hitachi, Япония).

Численную оптимизацию процесса каталитической пероксидной делигнификации древесины ели проводили с применением пакета прикладных программ Statgraphics Centurion XVI, блок DOE (Design of Experiment) [17].

\section{Результаты и обсуждение}

Ранее [18] при изучении процесса пероксидной делигнификации древесины березы в присутствии сернокислотного катализатора установлено, что практически полное удаление лигнина из древесины происходит при температуре $100{ }^{\circ} \mathrm{C}$, гидромодуле 15 и содержании $\mathrm{H}_{2} \mathrm{SO}_{4}$ $2 \%$ мас. Поэтому данные условия были выбраны для осуществления процесса пероксидной делигнификации древесины ели. Известно, что каталитическая добавка серной кислоты в реакционную смесь заметно ускоряет пероксидную делигнификацию и одновременно стабилизирует пероксид водорода [19].

Для оптимизации процесса пероксидной каталитической делигнификации древесины ели было изучено влияние концентрации пероксида водорода, уксусной кислоты, продолжительности процесса на выход целлюлозного продукта, динамику удаления лигнина и гемицеллюлоз из древесины, содержание целлюлозы в целлюлозном продукте.

Установлено, что значительное влияние на выход и состав целлюлозных продуктов оказывают начальные концентрации пероксида водорода и уксусной кислоты. При невысоких начальных концентрациях в реакционной смеси пероксида водорода (3 \% мас.) и уксусной кислоты (20 \% мас.), продолжительности делигнификации 2-4 ч получены целлюлозные продукты с выходом 66,3-51,8 \% от массы древесины. Однако продукты содержат еще достаточно много лигнина (21,6-6,6 \% мас.) и гемицеллюлоз 19,5-15,5 \% мас., имеют относительно невысокое содержание целлюлозы (59,0-77,0 \% мас.) (рис. 1a). При повышении в реакционной смеси начальной концентрации $\mathrm{H}_{2} \mathrm{O}_{2}$ до $5 \%$ мас. в тех же условиях делигнификации древесины ели выход целлюлозного продукта за 4 ч снизился до 47,6 \% мас. (рис. $1 b$ ). Вместе с тем содержание остаточного лигнина и гемицеллюлоз в продукте также уменьшилось до 4,4 и 13,0 \% мас. соответственно, а содержание целлюлозы возросло до $83,0 \%$ мас.

C ростом концентрации как $\mathrm{H}_{2} \mathrm{O}_{2}$, так и $\mathrm{CH}_{3} \mathrm{COOH}$ в реакционной среде при продолжительности процесса делигнификации 4 ч, наряду с уменьшением содержания остаточного лигнина и гемицеллюлоз, наблюдается снижение выхода целлюлозных продуктов из древесины ели с 51,8 до 41,0 \% мас. (рис. 2). Минимальное содержание остаточного лигнина (< 1,0 \% мас.) и гемицеллюлоз (< 7,0 \% мас.) имеют целлюлозные продукты, полученные при концентрации уксусной кислоты в реакционной среде 40 \% мас. Получена высококачественная целлюлоза с выходом 92,5-95,5 \% мас. от массы целлюлозного продукта. Таким образом, увеличение кон- 


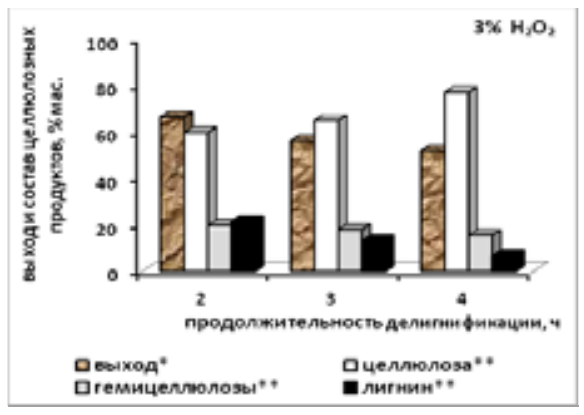

a

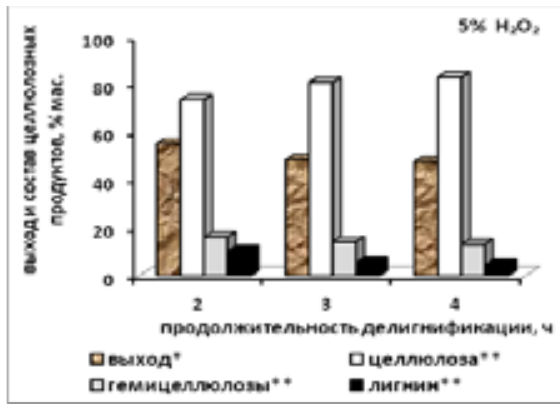

$b$

Рис. 1. Влияние концентрации $\mathrm{H}_{2} \mathrm{O}_{2}$ в реакционной смеси и продолжительности пероксидной каталитической делигнификации древесины ели на выход и состав целлюлозных продуктов (условия

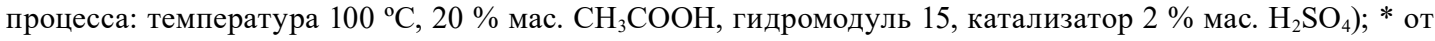
абс. сухой древесины, ** от абс. сухого целлюлозного продукта

Fig. 1. Influence of the $\mathrm{H}_{2} \mathrm{O}_{2}$ concentration in the reaction mixture and the duration of peroxide catalytic delignification of the fir wood on the yield and composition of the cellulosic products (process conditions: temperature $100{ }^{\circ} \mathrm{C}, \mathrm{CH}_{3} \mathrm{COOH} 20$ wt. \%, LWR 15 , catalyst $2 \%$ wt. $\left.\mathrm{H}_{2} \mathrm{SO}_{4}\right) *$ on abs. dry wood, ** on abs. dry cellulose product

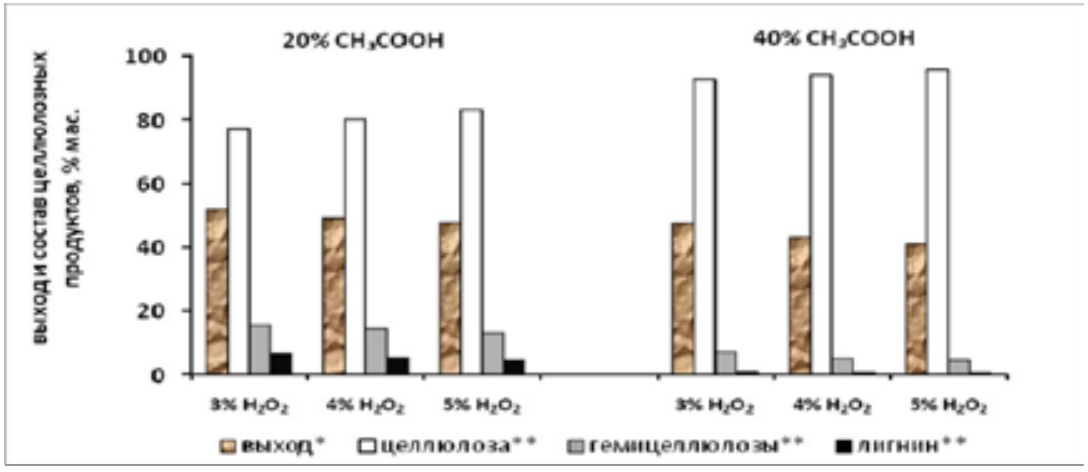

Рис. 2. Влияние концентрации $\mathrm{CH}_{3} \mathrm{COOH}$ и $\mathrm{H}_{2} \mathrm{O}_{2}$ в реакционной смеси на выход и состав целлюлозных продуктов, полученных пероксидной делигнификацией древесины ели (условия процесса: температура $100{ }^{\circ} \mathrm{C}$, гидромодуль 15 , продолжительность 4 ч, катализатор $\left.2 \% \mathrm{H}_{2} \mathrm{SO}_{4}\right)$; * от абс. сухой древесины, ** от абс. сухого целлюлозного продукта

Fig. 2. Influence of the $\mathrm{CH}_{3} \mathrm{COOH}$ and $\mathrm{H}_{2} \mathrm{O}_{2}$ concentrations in the reaction mixture on the yield and composition of the cellulosic products obtained by peroxide delignification of fir wood (process conditions: temperature 100 ${ }^{\circ} \mathrm{C}$, LWR 15 , the duration of $4 \mathrm{~h}$, catalyst $\left.2 \% \mathrm{wt} . \mathrm{H}_{2} \mathrm{SO}_{4}\right) *$ on abs. dry wood, $* *$ on abs. dry cellulose product

центрации уксусной кислоты в реакционной среде способствует более эффективному удалению лигнина и гемицеллюлоз.

На рис. 3 изображена зависимость динамики удаления лигнина из древесины ели от продолжительности процесса каталитической пероксидной делигнификации при температуре $100{ }^{\circ} \mathrm{C}$ и начальной концентрации реагентов $\mathrm{CH}_{3} \mathrm{COOH}$ и $\mathrm{H}_{2} \mathrm{O}_{2}$ в реакционной среде.

Из представленных данных видно, что при концентрации уксусной кислоты $20 \%$ мас. и пероксида водорода от 3 до 5 \% мас. в течение 4 ч делигнификации в продуктах остается 6,6-4,4 \% мас. лигнина. Дальнейшее повышение концентрации уксусной кислоты до 40 \% мас. 

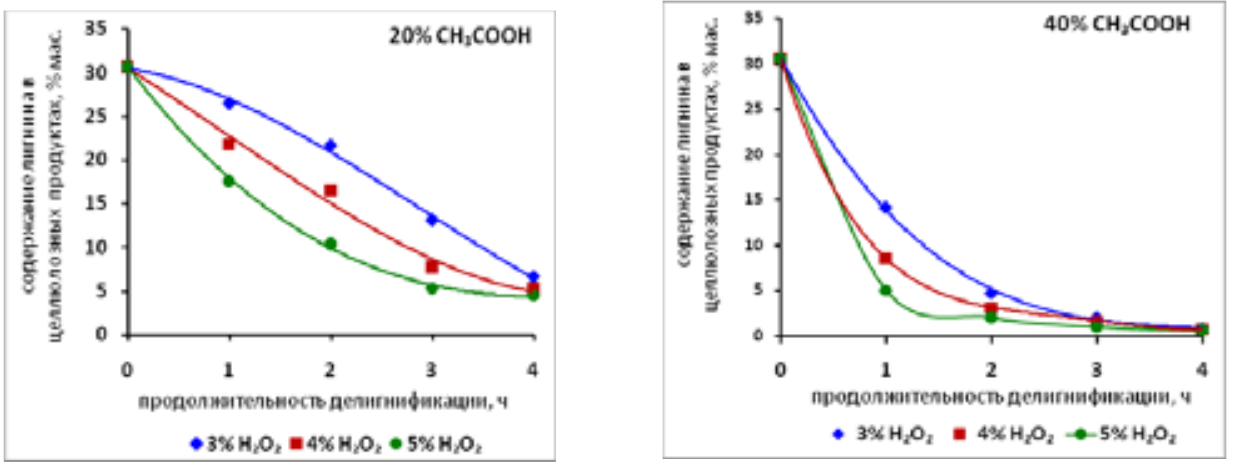

Рис. 3. Влияние концентрации $\mathrm{CH}_{3} \mathrm{COOH}$ и $\mathrm{H}_{2} \mathrm{O}_{2}$ в реакционной смеси, продолжительности пероксидной делигнификации древесины ели на содержание остаточного лигнина в целлюлозных продуктах (условия процесса: температура $100{ }^{\circ} \mathrm{C}$, гидромодуль 15 , катализатор $2 \%$ мас. $\mathrm{H}_{2} \mathrm{SO}_{4}$ )

Fig. 3. Influence of the $\mathrm{CH}_{3} \mathrm{COOH}$ and $\mathrm{H}_{2} \mathrm{O}_{2}$ concentrations in the reaction mixture, and the duration of fir wood peroxide delignification on the content of residual lignin in cellulose products (process conditions: temperature $100{ }^{\circ} \mathrm{C}$, LWR 15 , catalyst $2 \%$ wt. $\mathrm{H}_{2} \mathrm{SO}_{4}$ )

при прежних концентрациях пероксида водорода и продолжительности процесса приводит к уменьшению содержания лигнина в целлюлозных продуктах до 0,8-0,6 \% мас. соответственно. Следовательно, при повышении в реакционной среде концентрации уксусной кислоты происходит более полное удаление лигнина из древесины, чем при увеличении концентрации пероксида водорода.

Существуют воззрения [20], указывающие, что в присутствии $\mathrm{H}_{2} \mathrm{O}_{2}$ в растворе органической кислоты улучшается делигнификация лигноцеллюлозы за счет образования перуксусной кислоты, которая окисляет лигнин по электрофильному механизму [21].

$\mathrm{C}$ другой стороны, при повышенном содержании $\mathrm{H}_{2} \mathrm{O}_{2}$ в реакционном растворе пероксид водорода и перуксусная кислота легко распадаются с образованием радикалов НОं и НОО; которые осуществляют интенсивную окислительную деструкцию лигнина в кислой среде по гомолитическому механизму [22]. При этом происходит частичное окисление аморфной целлюлозы, что снижает выход целлюлозных продуктов.

Проведена математическая оптимизация состава варочного раствора и продолжительности процесса пероксидной делигнификации древесины ели для получения целлюлозного продукта с выходом не менее 45 \% мас., характеризующимся минимальным содержанием лигнина и гемицеллюлоз, максимальным содержанием целлюлозы.

В соответствии с полученными экспериментальными результатами в качестве переменных факторов использованы: $X_{1}$ - концентрация $\mathrm{CH}_{3} \mathrm{COOH}$ в реакционной среде (20-40), \% мас.; $X_{2}$ - концентрация $\mathrm{H}_{2} \mathrm{O}_{2}$ в реакционной среде (3-5), \% мас., $\mathrm{X}_{3}$ - продолжительность процесса делигнификации (2-4), ч. Выходные параметры: $Y_{1}$ - выход целлюлозного продукта, \% мас., $Y_{2}$ - содержание остаточного лигнина в целлюлозном продукте, \% мас., $Y_{3}-$ содержание гемицеллюлоз в целлюлозном продукте, \% мас., $Y_{4}$ - содержание целлюлозы в целлюлозном продукте, \% мас. Фиксированные условия: температура $100{ }^{\circ} \mathrm{C}$, катализатор $\mathrm{H}_{2} \mathrm{SO}_{4} 2$ \% мас., гидромодуль 15. Результаты реализации матрицы планирования приведены в табл. 1 . 
Таблица 1. Матрица оптимизации процесса каталитической пероксидной делигнификации древесины ели и результаты ее реализации

Table 1. Matrix of optimization of the process of fir wood peroxide delignification and the results of its implementation

\begin{tabular}{|c|c|c|c|c|c|c|c|}
\hline \multirow[b]{2}{*}{$\begin{array}{l}\frac{\pi}{b} \\
\vec{\theta} \\
0 \\
\text { 光 }\end{array}$} & \multirow{2}{*}{ 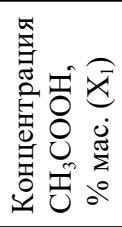 } & \multirow{2}{*}{ 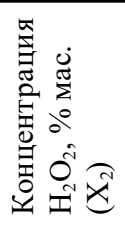 } & \multirow{2}{*}{ 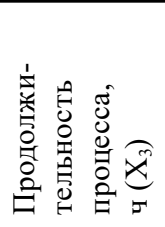 } & \multirow{2}{*}{ 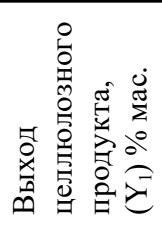 } & \multicolumn{3}{|c|}{$\begin{array}{c}\text { Содержание в целлюлозном } \\
\text { продукте, \% мас. }\end{array}$} \\
\hline & & & & & Лигнин $\left(\mathrm{Y}_{2}\right)$ & $\begin{array}{c}\text { Гемицел- } \\
\text { люлозы }\left(\mathrm{Y}_{3}\right)\end{array}$ & $\begin{array}{c}\text { Целлюлоза } \\
\left(\mathrm{Y}_{4}\right)\end{array}$ \\
\hline 1 & 20 & 3 & 2 & 66,3 & 21,6 & 19,5 & 59,0 \\
\hline 2 & 20 & 3 & 3 & 55,9 & 13,1 & 18,0 & 64,8 \\
\hline 3 & 20 & 3 & 4 & 51,8 & 6,6 & 15,5 & 77,0 \\
\hline 4 & 20 & 4 & 2 & 60,8 & 16,4 & 16,8 & 65,2 \\
\hline 5 & 20 & 4 & 3 & 54,3 & 7,7 & 15,2 & 76,5 \\
\hline 6 & 20 & 4 & 4 & 49,0 & 5,2 & 14,3 & 80,0 \\
\hline 7 & 20 & 5 & 2 & 55,2 & 10,3 & 16,0 & 73,6 \\
\hline 8 & 20 & 5 & 3 & 48,5 & 5,3 & 14,1 & 80,8 \\
\hline 9 & 20 & 5 & 4 & 47,6 & 4,4 & 13,0 & 83,0 \\
\hline 10 & 30 & 3 & 2 & 57,4 & 9,7 & 15,0 & 75,3 \\
\hline 11 & 30 & 3 & 3 & 52,8 & 4,5 & 13,8 & 81,6 \\
\hline 12 & 30 & 3 & 4 & 50,3 & 2,9 & 12,0 & 85,1 \\
\hline 13 & 30 & 4 & 2 & 53,0 & 6,6 & 15,0 & 77,6 \\
\hline 14 & 30 & 4 & 3 & 50,0 & 4,0 & 12,2 & 83,2 \\
\hline 15 & 30 & 4 & 4 & 48,2 & 2,7 & 10,8 & 86,4 \\
\hline 16 & 30 & 5 & 2 & 49,4 & 3,6 & 14,5 & 82,0 \\
\hline 17 & 30 & 5 & 3 & 47,9 & 2,7 & 12,0 & 85,3 \\
\hline 18 & 30 & 5 & 4 & 45,3 & 1,5 & 10,0 & 88,5 \\
\hline 19 & 40 & 3 & 2 & 49,7 & 4,7 & 10,0 & 86,0 \\
\hline 20 & 40 & 3 & 3 & 49,3 & 2,2 & 8,5 & 90,3 \\
\hline 21 & 40 & 3 & 4 & 47,4 & 0,8 & 7,1 & 92,5 \\
\hline 22 & 40 & 4 & 2 & 47,6 & 3,1 & 8,3 & 89,0 \\
\hline 23 & 40 & 4 & 3 & 46,0 & 1,6 & 6,5 & 92,2 \\
\hline 24 & 40 & 4 & 4 & 43,2 & 0,7 & 5,0 & 94,0 \\
\hline 25 & 40 & 5 & 2 & 45,5 & 2,5 & 7,0 & 91,1 \\
\hline 26 & 40 & 5 & 3 & 43,2 & 1,0 & 5,0 & 94,3 \\
\hline 27 & 40 & 5 & 4 & 40,9 & 0,6 & 4,5 & 95,5 \\
\hline
\end{tabular}

Оптимизация сводится к поиску в пределах изученного факторного пространства условий, обеспечивающих $Y_{1} \geq 45 \%$ мac., $Y_{2} \rightarrow \min , Y_{3} \rightarrow \min , Y_{4} \rightarrow \max$. Ограничения области поиска решения в факторном пространстве для процесса делигнификации составляют $20 \leq X_{1} \leq 40 ; 3 \leq$ $X_{2} \leq 5 ; 2 \leq X_{3} \leq 4$. Результаты дисперсионного анализа представлены в табл. 2 .

Дисперсионный анализ выходных параметров $\mathrm{Y}_{1}, \mathrm{Y}_{2}, \mathrm{Y}_{3}$ и $\mathrm{Y}_{4}$ выявил существенное влияние всех трех главных факторов на достоверность модели каталитической пероксидной делиг- 
Таблица 2. Результаты дисперсионного анализа выходных параметров $\mathrm{Y}_{1}, \mathrm{Y}_{2}, \mathrm{Y}_{3}$ и $\mathrm{Y}_{4}$

Table 2. Results of dispersion analysis of output parameters $\mathrm{Y}_{1}, \mathrm{Y}_{2}, \mathrm{Y}_{3}$ and $\mathrm{Y}_{4}$

\begin{tabular}{|c|c|c|c|c|c|c|c|c|}
\hline \multirow[b]{2}{*}{$\begin{array}{l}\text { Источники } \\
\text { дисперсии }\end{array}$} & \multicolumn{2}{|c|}{$Y_{1}$} & \multicolumn{2}{|c|}{$Y_{2}$} & \multicolumn{2}{|c|}{$Y_{3}$} & \multicolumn{2}{|c|}{$Y_{4}$} \\
\hline & 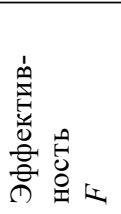 & 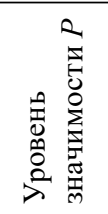 & 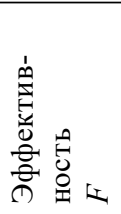 & 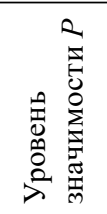 & 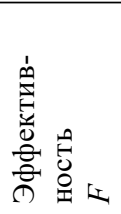 & 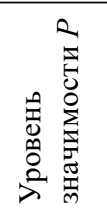 & 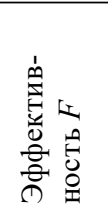 & 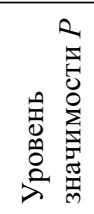 \\
\hline $\mathrm{X}_{1}$ & 152,52 & 0,0000 & 246,38 & 0,0000 & 113,62 & 0,0000 & 184,59 & 0,0000 \\
\hline $\mathrm{X}_{2}$ & 79,78 & 0,0000 & 54,50 & 0,0000 & 45,85 & 0,0000 & 51,48 & 0,0000 \\
\hline $\mathrm{X}_{3}$ & 93,89 & 0,0000 & 137,19 & 0,0000 & 29,63 & 0,0000 & $\begin{array}{l}78,38 \\
\end{array}$ & 0,0000 \\
\hline $\mathrm{X}_{1}^{2}$ & 0,00 & 0,9854 & 14,34 & 0,0013 & 0,11 & 0,7465 & 3,96 & 0,6598 \\
\hline $\mathrm{X}_{1} \mathrm{X}_{2}$ & 1,36 & 0,2601 & 22,28 & 0,0002 & 17,68 & 0,0006 & 29,78 & 0,0000 \\
\hline $\mathrm{X}_{1} \mathrm{X}_{3}$ & 19,91 & 0,0003 & 43,59 & 0,0000 & 4,87 & 0,0414 & 31,19 & 0,0000 \\
\hline $\mathrm{X}_{2}^{2}$ & 0,00 & 0,9707 & 0,23 & 0,6395 & 0,39 & 0,5408 & 1,23 & 0,8320 \\
\hline $\mathrm{X}_{2} \mathrm{X}_{3}$ & 2,25 & 0,1518 & 17,55 & 0,0006 & 0,29 & 0,6001 & 6,22 & 0,0203 \\
\hline $\mathrm{X}_{3}^{2}$ & 2,14 & 0,1621 & 5,58 & 0,0296 & 0,39 & 0,5408 & 3,28 & 0,1566 \\
\hline $\mathrm{R}^{2}, \%$ & \multicolumn{2}{|c|}{95,0} & \multicolumn{2}{|c|}{96,8} & \multicolumn{2}{|c|}{95,6} & \multicolumn{2}{|c|}{97,8} \\
\hline
\end{tabular}

нификации древесины ели. На это указывают высокие значения дисперсионных отношений $\mathrm{F}$ и низкий уровень значимости Р $(<0,05)$. Члены второго порядка (квадратичные члены и парное взаимодействие) оказались статистически незначимы для зависимости выхода целлюлозного продукта $\left(Y_{1}\right)$, содержания остаточных гемицеллюлоз $\left(Y_{3}\right)$ и содержания целлюлозы $\left(Y_{4}\right)$ в целлюлозном продукте от переменных факторов каталитической пероксидной делигнификации. В соответствии с этим в уравнениях регрессии $1,3,4$ оставлены только главные эффекты. Для зависимости содержания остаточного лигнина $\left(Y_{2}\right)$ в целлюлозном продукте от переменных факторов делигнификации оказался несущественным только вклад источника дисперсии $X_{2}^{2}$ (исключен из уравнения 2). Зависимости $Y_{1}, Y_{2}, Y_{3}, Y_{4}$ от переменных факторов $X_{1}, X_{2}, X_{3}$ процесса пероксидной делигнификации древесины ели аппроксимируются следующими уравнениями регрессии:

$$
\begin{aligned}
& Y_{1}=50,2407-4,25556 \cdot X_{1}-3,18889 \cdot X_{2}-3,4 \cdot X_{3}+1,88333 \cdot X_{1} \cdot X_{3} \\
& Y_{2}=3,54444-4,02778 \cdot X_{1}-1,89444 \cdot X_{2}-3,00556 \cdot X_{3}+1,68333 \cdot X_{1}^{2}+ \\
& +1,48333 \cdot X_{1} \cdot X_{2}+2,075 \cdot X_{1} \cdot X_{3}+1,31667 \cdot X_{2} \cdot X_{3}+1,05 \cdot X_{3}^{2} \\
& Y_{3}=11,837-4,47222 \cdot X_{1}-1,29444 \cdot X_{2}-1,66111 \cdot X_{3}+0,0666667 \cdot X_{1} \cdot X_{2}+ \\
& +0,0666667 \cdot X_{1} \cdot X_{3} ; \\
& Y_{4}=82,5852+9,16667 \cdot \mathrm{X}_{1}+3,47222 \cdot \mathrm{X}_{2}+4,62222 \cdot \mathrm{X}_{3}-2,04167 \cdot \mathrm{X}_{1} \cdot \mathrm{X}_{2^{-}} \\
& -2,19167 \cdot \mathrm{X}_{1} \cdot \mathrm{X}_{3}-1,16667 \cdot \mathrm{X}_{2} \cdot \mathrm{X}_{3} .
\end{aligned}
$$

Об удовлетворительных прогностических свойствах уравнений 1-4 свидетельствуют высокие значения коэффициентов детерминации $R^{2}: 95.0 \%, 96.8 \%, 95.6 \%, 97.8 \%$.

$$
-597-
$$


Графическое отображение в виде поверхности отклика зависимости выхода целлюлозного продукта от переменных факторов процесса делигнификации древесины ели представлено на рис. 4. Полученная графическая зависимость является ровной поверхностью с легким наклоном в сторону увеличения концентрации уксусной кислоты. Оптимальное прогнозируемое значение выхода целлюлозного продукта 45 мас. \% достигается в точке, которая соответствует концентрации $\mathrm{CH}_{3} \mathrm{COOH}$ - 38,1 \% мас., $\mathrm{H}_{2} \mathrm{O}_{2}-4,4$ \% мас. и продолжительности делигнификации 3,2 ч. Это решение близко к условиям опыта № 23 (табл. 1).

Дисперсионный анализ данных показал, что на содержание остаточного лигнина в целлюлозном продукте, помимо главных переменных факторов процесса делигнификации, оказали влияние почти все второстепенные источники дисперсии (табл. 2). Поверхность отклика, соответствующая уравнению 2 , изображена на рис. 5 . Увеличение концентрации уксусной кислоты и продолжительности делигнификации даже при начальной концентрации пероксида водорода $3 \%$ мас. приводит к существенному снижению содержания остаточного лигнина в целлюлозных продуктах. Прогнозируемое минимальное содержание лигнина в целлюлозном продукте составляет $0,7 \%$ мас. и достигается в точке, соответствующей следующим значениям переменных факторов: концентрация $\mathrm{CH}_{3} \mathrm{COOH}-38,9$ мас. \%, $\mathrm{H}_{2} \mathrm{O}_{2}-3$ мас. \%, продолжительность делигнификации 4 ч. Решение близко к условиям и результатам опыта № 21 (табл. 1).

Аналогичным образом проанализировано влияние переменных факторов в процессе делигнификации древесины ели на содержание гемицеллюлоз в целлюлозном продукте. Поверхность отклика, соответствующая уравнению 3, имеет вид «горки» (рис. 6). Содержание гемицеллюлоз в целлюлозном продукте плавно снижается с увеличением концентрации уксусной кислоты в реакционной среде. Прогнозируемое значение содержания гемицеллюлоз в продукте составит 4,8 мас. \% и может быть достигнуто при концентрации $\mathrm{CH}_{3} \mathrm{COOH}-40 \%$ мас., $\mathrm{H}_{2} \mathrm{O}_{2}-$ 4,0 \% мас., продолжительности процесса 4 ч. Это решение соответствует условиям опыта № 24 (табл. 1), которые обеспечивают содержание гемицеллюлоз 5,0 \% мас. и низкое содержание лигнина (0,7 \% мас.) в целлюлозном продукте.

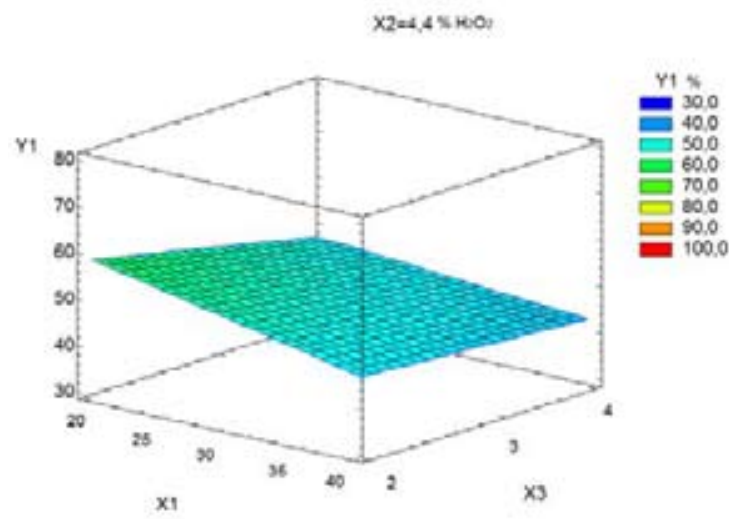

Рис. 4. Поверхность отклика выходного параметра $Y_{l}$ (выход целлюлозного продукта, \% мас.) от концентрации уксусной кислоты $\left(X_{1}, \%\right.$ мас.) и продолжительности процесса $\left(X_{3}\right.$, ч) каталитической пероксидной делигнификации древесины ели

Fig. 4. Response surface of output parameter $Y_{l}$ (cellulose product yield, \% wt.) on concentration of acetic acid $\left(X_{1}, \mathrm{wt} \%\right)$ and on the duration $\left(X_{3}, \mathrm{~h}\right)$ of the process of fir wood catalytic peroxide delignification 


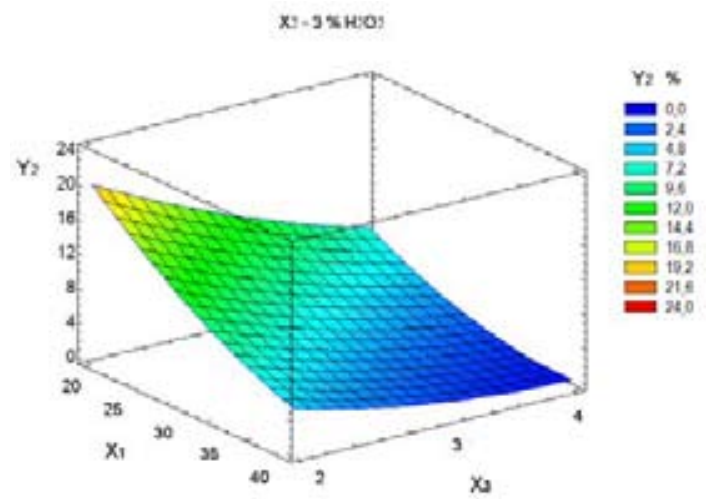

Рис. 5. Поверхность отклика выходного параметра $Y_{2}$ (содержание остаточного лигнина в целлюлозном продукте, \% мас.) от концентрации уксусной кислоты ( $X_{1}$, \% мас.) и продолжительности процесса $\left(X_{3}\right.$, ч) - каталитической пероксидной делигнификации древесины ели

Fig. 5. Response surface of output parameter $Y_{2}$ (content of residual lignin in cellulosic product, \% wt.) on concentration of acetic acid $\left(X_{1}\right.$, wt \%) and on the duration $\left(X_{3}, \mathrm{~h}\right)$ of the process of fir wood catalytic peroxide delignification

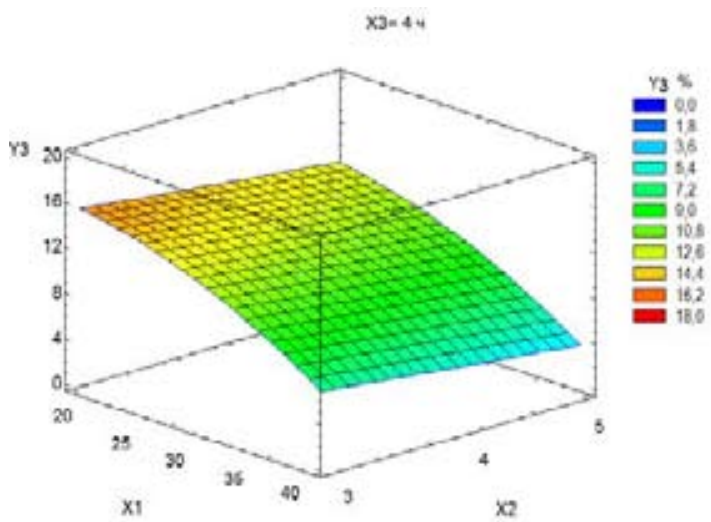

Рис. 6. Поверхность отклика выходного параметра $Y_{3}$ (содержание остаточных гемицеллюлоз в целлюлозном продукте, \% мас.) от концентрации уксусной кислоты ( $X_{1}, \%$ мac.) и пероксида водорода $\left(X_{2}, \%\right.$ мac.) в процессе каталитической пероксидной делигнификации древесины ели

Fig. 6. Response surface of output parameter $Y_{3}$ (content of residual hemicelluloses in cellulosic product, \% wt.) on concentrations of acetic acid $\left(X_{1}, \mathrm{wt} \%\right)$ and hydrogen peroxide $\left(X_{2}\right.$, wt \%) of the process of fir wood catalytic peroxide delignification

Зависимость содержания целлюлозы в целлюлозном продукте от переменных факторов процесса пероксидной делигнификации древесины ели в присутствии сернокислотного катализатора соответствует уравнению регрессии 4. Графическое отображение найденной зависимости в виде поверхности отклика представлено на рис. 7. Увеличение концентрации уксусной кислоты и продолжительности делигнификации приводит к резкому увеличению содержания целлюлозы в целлюлозном продукте из древесины ели даже при начальной концентрации пероксида водорода 3,8 \% мас. Прогнозируемое содержание целлюлозы в продукте составит 94,4 мас. \% и может быть достигнуто при следующих условиях: концентрация $\mathrm{CH}_{3} \mathrm{COOH}-$ 
40 \% мас., $\mathrm{H}_{2} \mathrm{O}_{2}-3,8$ \% мас., продолжительность процесса 3,4 ч. Это решение близко к условиям опыта № 24 (табл. 1).

Рассчитанные оптимальные значения переменных факторов и выходных параметров процесса пероксидной каталитической делигнификации древесины ели хорошо коррелируют с экспериментальными данными (табл. 3).

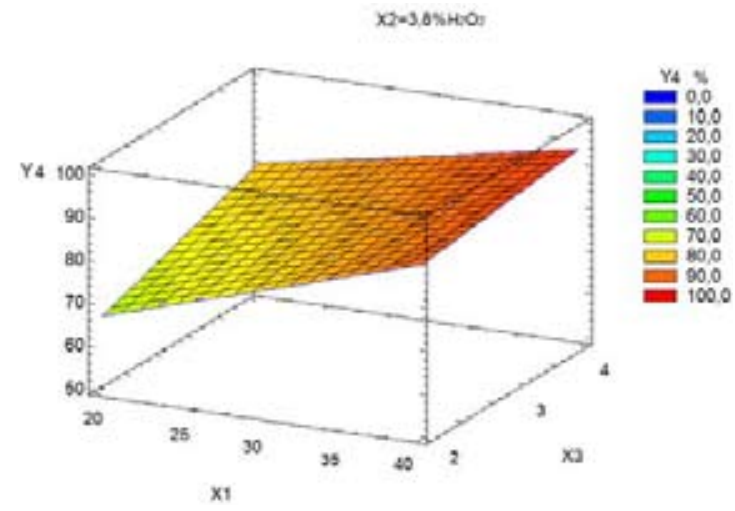

Рис. 7. Поверхность отклика выходного параметра $Y_{4}$ (содержание целлюлозы в целлюлозном продукте, \% мас.) от концентрации уксусной кислоты $\left(X_{1}, \%\right.$ мас.) и продолжительности $\left(X_{3}\right.$, ч) процесса каталитической пероксидной делигнификации древесины ели

Fig. 7. Response surface of output parameter $Y_{4}$ (content of residual lignin in cellulosic product, \% wt.) on acetic acid concentration $\left(X_{1}\right.$, wt $\left.\%\right)$ and on duration $\left(X_{3}, \mathrm{~h}\right)$ of the process of fir wood catalytic peroxide delignification

Таблица 3. Сопоставление оптимальных значений переменных факторов и выходных параметров процесса пероксидной каталитической делигнификации древесины ели, полученных экспериментально и расчетным путем (температура $100{ }^{\circ} \mathrm{C}$, гидромодуль 15 , катализатор $2 \%$ мас. $\mathrm{H}_{2} \mathrm{SO}_{4}$ )

Table 3. Comparison of the optimal values of variable factors and of output parameters of the process of fir wood catalytic peroxide delignification obtained experimentally and by calculation (temperature $100{ }^{\circ} \mathrm{C}$, LWR 15 , catalyst $2 \%$ wt. $\mathrm{H}_{2} \mathrm{SO}_{4}$ )

\begin{tabular}{|c|c|c|c|c|c|c|c|c|c|}
\hline \multirow[b]{3}{*}{ № пா } & \multicolumn{6}{|c|}{ Переменные факторы } & \multicolumn{3}{|c|}{ Выходные параметры } \\
\hline & \multicolumn{3}{|c|}{ расчетные значения } & \multicolumn{3}{|c|}{$\begin{array}{c}\text { экспериментальные } \\
\text { значения }\end{array}$} & \multirow[b]{2}{*}{$\begin{array}{c}\text { наименование } \\
\text { параметра }\end{array}$} & \multirow[b]{2}{*}{$\begin{array}{c}\text { расчетные } \\
\text { значения }\end{array}$} & \multirow[b]{2}{*}{$\begin{array}{c}\text { экспери- } \\
\text { ментальные } \\
\text { значения }\end{array}$} \\
\hline & 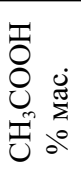 & 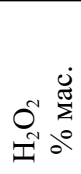 & 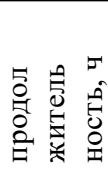 & 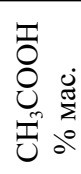 & 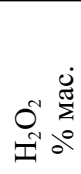 & 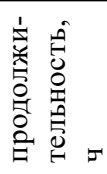 & & & \\
\hline 1 & 38,1 & 4,4 & 3,2 & 40,0 & 4,0 & 3,0 & $\begin{array}{l}\text { выход } \\
\text { целлюлозного } \\
\text { продукта, \%* мас. }\end{array}$ & 45,0 & 46,0 \\
\hline 2 & 38,9 & 3,0 & 4,0 & 40,0 & 3,0 & 4,0 & лигнин, \%** мас. & 0,7 & 0,8 \\
\hline 3 & 40,0 & 4,0 & 4,0 & 40,0 & 4,0 & 4,0 & $\begin{array}{l}\text { гемицеллюлозы, } \\
\text { \%** мас. }\end{array}$ & 4,8 & 5,0 \\
\hline 4 & 40,0 & 3,8 & 3,4 & 40,0 & 4,0 & 4,0 & $\begin{array}{l}\text { целлюлоза, \%** } \\
\text { мас. }\end{array}$ & 94,3 & 94,0 \\
\hline
\end{tabular}

* От массы абс. сухой древесины, ** от массы абс. сухого целлюлозного продукта. 


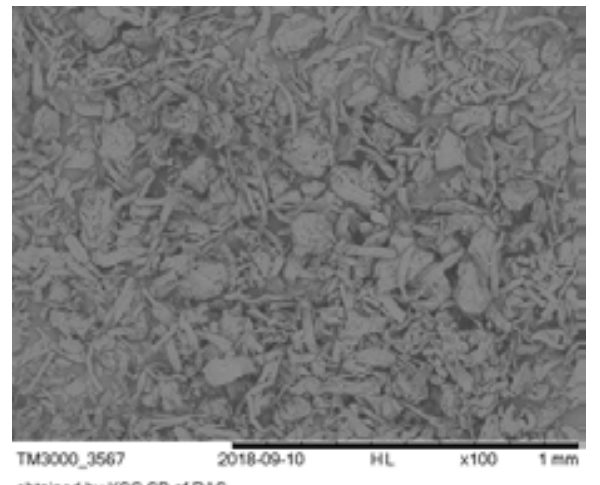

obtained by KSC SB of RAS

$a$

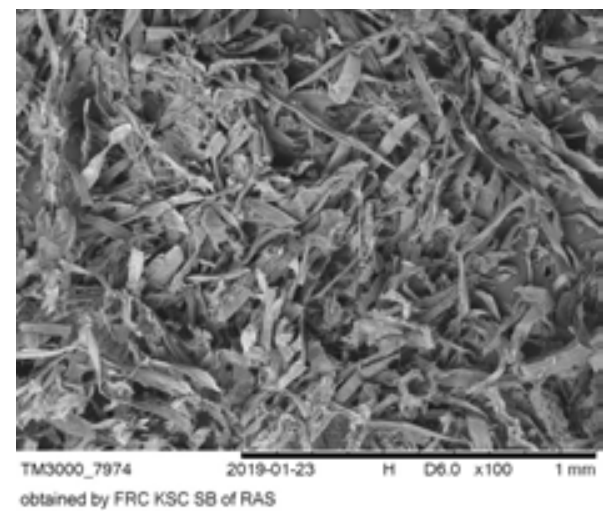

$b$

Рис. 8. Электронно-микроскопические снимки образцов промышленной целлюлозы Vivapur $101(a)$ и целлюлозы ели $(b)$

Fig. 8. SEM images of cellulose Vivapur $101(a)$ and cellulose obtained from fir wood $(b)$

В оптимальных условиях делигнификации древесины ели, обеспечивающих минимальное содержание остаточного лигнина (№ 2, табл. 3), выход целлюлозного продукта составил 45.5 \% мас., а содержание в нем целлюлозы, гемицеллюлоз и лигнина - 93.5, 6.0 и 0.8 \% мас. соответственно. Полученный целлюлозный продукт по своему составу является высококачественной целлюлозой.

Были сопоставлены электронно-микроскопические снимки образцов промышленной целлюлозы Vivapur 101 и целлюлозы из древесины ели (рис. 8). Образец целлюлозы Vivapur 101 состоит из отдельных волокон и групп волокон, свернутых в сферические глобулы, размером около 100 мкм (рис. 8a). Целлюлоза, полученная в оптимальных условиях пероксидной делигнификации древесины ели, состоит из сравнительно однородных частиц - отдельных волокон шириной около 20-50 мкм и длиной около 0,5-1 мм (рис. $8 b$ ).

ИК-спектры образца целлюлозы, полученной пероксидной каталитической делигнификацией древесины ели в оптимальных условиях, и коммерческой целлюлозы Vivapur 101 практически идентичны.

\section{Заключение}

Изучены закономерности процесса пероксидной делигнификации древесины ели в среде «уксусная кислота - вода - катализатор $\mathrm{H}_{2} \mathrm{SO}_{4}$ » в мягких условиях $\left(100{ }^{\circ} \mathrm{C}\right.$, атмосферное давление).

Установлена возможность получения из древесины ели в одну стадию качественной целлюлозы с содержанием остаточного лигнина $<1 \%$ мас. при низкой концентрации пероксида водорода (3\% мас.) в реакционной среде. Установлено, что увеличение концентрации уксусной кислоты с 20 до 40 \% мас. способствует более эффективному удалению лигнина и гемицеллюлоз из древесины ели при продолжительности делигнификации от 2 до 4 ч.

Экспериментальными и расчетными методами определены оптимальные концентрации реагентов $\left(\mathrm{H}_{2} \mathrm{O}_{2}-3 \%\right.$ мас., $\mathrm{CH}_{3} \mathrm{COOH}-38,9$ \% мас.) и продолжительность процесса (4 ч), обес-

$$
-601-
$$


печивающие получение из древесины ели целлюлозного продукта с выходом $\geq 45 \%$ мас. и содержанием остаточного лигнина $<1$ \% мас. По химическому составу полученный целлюлозный продукт является качественной целлюлозой, которая состоит из сравнительно однородных частиц - отдельных волокон шириной около 20-50 мкм и длиной около 0,5-1 мм.

Работа выполнена в рамках государственного задания Института химии и химической технологии СО РАН (проект АААА-А17-117021310218-7) с использованием оборудования Красноярского регионального центра коллективного пользования ФИЦ КНЦ СО РАН.

\section{Список литературы}

1. Wadenbäck J., Clapham D.H, Gellerstedt G., Arnold S. Variation in content and composition of lignin in young wood of Norway spruce. Holzforschung 2004. Vol. 58(2), P. 107-115.

2. Jönsson J., Pettersson K., Berntsson T., Harvey S. Comparison of options for utilization of a potential steam surplus at kraft pulp mills. International Journal of Energy Research 2013. Vol. 37, P. 1017-1035.

3. Kuznetsov B.N., Taraban'ko V.E., Kuznetsova S.A. New catalytic methods for obtaining cellulose and other chemical products from vegetable biomass. Kinetics and Catalysis 2008. Vol. 49 (4), P. 517-526.

4. Sixta J.V., van Heiningen H., Multistage A. Multistage oxygen delignification of high-kappa pine kraft pulp with peroxymonosulfuric acid (Px) Holzforschung 2014. Vol. 68 (5), P. 497-504.

5. Akim L.G., Colodette J.L., Argyropoulos D.S. Factors limiting oxygen delignification of kraft pulp. Canadian Journal of Chemistry 2011. Vol. 79(2), P. 201-210.

6. Kuznetsov B.N., Kuznetsova S.A., Danilov V.G., Yatsenkova O.V., Petrov A.V. A green one step process of obtaining microcrystalline cellulose by catalytic oxidation of wood. Reaction Kinetics, Mechanisms and Catalysis 2011. Vol. 104, P. 337-343.

7. Кузнецов Б.Н., Кузнецова С.А., Яценкова О.В., Данилов В.Г. Получение целлюлозы каталитической делигнификацией древесины пероксидом водорода: монография. Красноярск, 2014. 146 c. [Kuznetsov B.N., Kuznetsova S.A., Iatsenkova O.V., Danilov V.G. Production of cellulose by catalytic delignification of wood by hydrogen peroxide: monograph. Krasnoiarsk, 2014, 146 p. (In Russ.).]

8. Kuznetsov B.N., Garyntseva N.V., Sudakova I.G., Djakovitch L., Pinel C. Kinetic study of aspen-wood sawdust delignification by $\mathrm{H}_{2} \mathrm{O}_{2}$ with sulfuric acid catalyst under the mild conditions. Reaction Kinetics Mechanisms and Catalysis 2013. Vol. 110, P.271-280.

9. Судакова И.Г., Гарынцева Н.В., Яценкова О.В., Кузнецов Б.Н. Оптимизация процесса делигнификации древесины осины пероксидом водорода в присутствии сернокислотного катализатора. Журнал Сибирского федерального университета. Химия 2013. Т. 6(1), С. 76-84. [Sudakova I.G., Garyntseva N.V., Yatsenkova O.V., Kuznetsov B.N. Optimization of aspen wood delignification by $\mathrm{H}_{2} \mathrm{O}_{2}$ with sulfuric acid catalyst. Journal of Siberian Federal University. Chemistry. 2013. Vol. 6(1), P. 76-84. (In Russ.)].

10. Судакова И.Г., Гарынцева Н.В., Чудина А.И., Кузнецов Б.Н. Закономерности процесса пероксидной делигнификации древесины сосны в присутствии сернокислотного катализатора. Химия растительного сырья 2018. № 4, С. 63-71. [Sudakova I.G., Garyntseva N.V., Chudina A.I., 
Kuznetsov B.N. Khimiya Rastitel'nogo Syr'ya, 2018, no. 4, P. 63-71. (In Russ.)] DOI: 10.14258/ jcprm.2018044079

11. Suchy M., Argyropoulos D. S. Catalysis and activation of oxygen and peroxide delignification of chemical pulps: a review. Tappi Journal 2002. Vol. 1(2), P. 1-18.

12. Bas D., Boyaci I.H. Modeling and optimization I: Usability of response resurface methodology. Journal of Food Engineering 2007. Vol. 78, P. 836-845. dx.doi.org/10.1016/j. jfoodeng.2005.11.024

13. Sjöström E., Alen R. Analytical methods of wood chemistry. Pulping and papermaking. Berlin, Springer-Verlag, 1999. 318 p.

14. Tappi, 2009. Carbohydrate composition of extractive-free wood and wood pulp by gas-liquid chromatography (Reaffirmation of T $249 \mathrm{~cm}-09$ ).

15. Ruiz-Matute A.I., Hernandez-Hernandez O., Rodriguez-Sanchez S., Sanz M.L., Martinez Castro I. Derivatization of carbohydrates for GC and GC-MS analyses. J. Chromatogr. B 2011. Vol. 879, P. 1226-1240.

16. Sluiter J. B., Ruiz R. O., Scarlata CH. J., Sluiter A. D., Templeton D. W. Compositional analysis of lignocellulosic feedstocks. 1. Review and description of methods J. Agric. Food Chem. 2010. Vol. 58, P. 9043-9053.

17. Kuznetsov B.N., Sudakova I.G., Yatsenkova O.V., Garyntseva N.V., Rataboul F., Djakovitch L. Optimization of One-Stage Processes of Microcrystalline Cellulose Obtaining by Peroxide Delignification of Wood in the Presence of $\mathrm{TiO}_{2}$ Catalyst Kataliz v promyshlennosti 2018. Vol. 18(3), P. 72-80. (In Russ.)

18. Kuznetsov B.N., Kuznetsova S.A., Levdansky V.A., Levdansky A.V., Vasil'eva N.Yu., Chesnokov N.V., Ivanchenko N.M., Djakovitch L. and Pinel C. Optimized methods for obtaining cellulose and cellulose sulfates from birch wood. Wood Science and Technology 2015. Vol. 49 (4), P. 825-843. DOI 10.1007/500226-015-0723-y.

19. He Tan, Rallming Yang, Weidong Sun Peroxide-Acetic Acid Pretreatment To Remove Bagasse Lignin Prior to Enzymatic Hydrolysis. Ind. Eng. Chem. Res. 2010. Vol. 49(4), P.1473-1479.

20. Kham L., Le Bigot Y., Delmas M., Avignon G. Delignification of wheat straw using a mixture of carboxylic acids and peroxoacids. Industrial Crops and Products 2005. Vol. 21(1), P. 9-15.

21. Ma R., Xu Y., Zhang X. Catalytic oxidation of biorefinery lignin to value-added chemicals to support sustainable biofuel production. Chem Sus Chem 2015. Vol. 8, P. 24-51.

22. Posoknistakul P, Akiyama T, Yokoyama T, Matsumoto Y. Stereo-preference in the degradation of the erythro and threoisomers of $\beta$-O-4-type lignin model compounds in oxidation process: part 2 : In the reaction with hydroxyl and oxyl anion radicals under hydrogen peroxide bleaching conditions. J. Wood Chem Technol 2017. Vol. 37, P. 87-98.

23. Ghaffar S. H., Fan M. Structural analysis for lignin characteristics in biomass straw. Biomass and Bioenergy 2013. Vol. 57, P. 264-279.

24. Xu, Feng, Yu, Jianming, Tesso, Tesfaye, Dowell, Floyd, Wang, Donghai. Qualitative and quantitative analysis of lignocellulosic biomass using infrared techniques: A mini-review. Applied Energy 2013. Vol. 104, P. 801-809.

25. Carrillo, I., Mendonça, R.T., Ago, M., Rojas, O.J. Comparative study of cellulosic components isolated from different Eucalyptus species. Cellulose 2018. Vol.25, P. 1011-1029.

$$
-603-
$$

